\title{
Algunas reflexiones sobre la ley aplicable a la separación judicial y al divorcio en el Derecho internacional privado español
}

\author{
María Dolores Adam Muñoz \\ Profesora Titular de Derecho Internacional Privado \\ Universidad de Córdoba
}

Recibido: 08.07 .08

Aceptado: 22.10 .08

Resumen: El estudio analiza el artículo 107.2 del Código civil, norma de Derecho internacional privado español aplicable a la separación judicial y el divorcio, según la reforma operada por la Ley 11/2003 de 29 de septiembre. En él se analizan las deficiencias de la anterior normativa y los motivos que dieron lugar a la modificación de este precepto, que había sido reclamada por la doctrina en numerosas ocasiones. El detonante de la reforma radica en una recomendación del Defensor del Pueblo al Ministerio de Justicia, según la cual se instaba a que la norma de Derecho internacional privado contemplara la posibilidad de que, a elección de la parte demandante, la separación judicial o el divorcio se pudieran regir, bien por la ley de la nacionalidad común de los cónyuges, o bien por la ley de la última residencia habitual común, siempre que ésta estuviera en España. Sin embargo, la transformación realizada por el legislador ha querido ser mucho más ambiciosa y no limitarse a reconocer la autonomía de la voluntad, lo cual, en realidad, no efectúa, y establece una regulación confusa, incoherente, vaga y equívoca, entre otras consideraciones. Estas imprecisiones son puestas de relieve en este trabajo, a la vez que se aportan distintas posibles soluciones para la regulación de la separación judicial y el divorcio internacionales.

Palabras clave: Crisis matrimoniales internacionales. Separación judicial. Divorcio. Repudio. Ley aplicable. Autonomía de la voluntad. Alegación y prueba del Derecho extranjero. Excepción de orden público internacional.

Abstract: The research analyzes the article 107.2 of the Civil Code, Spanish International Private Law. It is applicable to the court separation and divorce, according to the reform operated on the Law 11/2003 on the date September $29^{\text {th }}$. The faults of the previous regulation and the reason that provoke the modification of this precept - which has been claimed in numerous occasions-are analyzed in this research itself. The trigger of the reform lies in a recommendation by the People Defence Lawyer to the Ministry of Justice. According to it, the International Private Law would contemplate the possibility of-being elected by the plaintiff part- the court separation or divorce could be governed, either by the common nationality law of the spouses, or by the last common habitual residence law (always this residence were located in Spain). However, the transformation made by the legislator in more ambitious and does not finish with recognizing the intention of autonomy, which, in fact, does not execute it, and establishes an unclear, incoherent, vague and wrong regulation. This imprecision is lent with special importance in this essay. At the same time, it contributes with diffe- 
rent possible solutions for the regulation of the international court separation and divorce.

Key words: International marital crisis. Court separation. Divorce. Applicable law. Intention of autonomy. Declaration and proof of foreign law. International public order exception.

Sumario: I. Introducción. El artículo 107 del Código civil según el contenido otorgado por la Ley 30/1981 de 7 de julio.--II. La reforma del artículo 107.2 del Código civil. 1. Iniciativa de la reforma legislativa: la recomendación del Defensor del Pueblo. 2. La respuesta legislativa a las demandas realizadas por el Defensor del Pueblo.--III. Contenido de la reforma legislativa: análisis de los distintos supuestos contemplados por el artículo 107 del Código civil. 1. El inciso primero del artículo 107.2 del Código civil: conexiones utilizadas. 2. Segundo inciso del artículo 107.2 del código civil: conexiones utilizadas.-IV. Bases para una reforma del artículo 107.2 del Código civil._Conclusiones.

\section{INTRODUCCIÓN. EL ARTÍCULO 107 DEL CÓDIGO CIVIL SEGÚN EL CONTENIDO OTORGADO POR LA LEY 30/1981 DE 7 JULIO}

La Ley 30/1981 de 7 de julio por la cual se introduce nuevamente el divorcio en nuestro país establece una norma específica para la separación judicial y el divorcio en el ámbito del Derecho internacional privado contenida en el artículo 107 del Código civil. Este precepto establecía como ley aplicable a estas situaciones, en primer lugar, la ley nacional común de los cónyuges al tiempo de presentación de la demanda, en defecto de esta ley, la de la residencia habitual común del matrimonio y, si los esposos tuvieren su residencia habitual en diferentes Estados, la ley española, siempre que los tribunales españoles resultaran competentes.

Los comentarios e interpretaciones vertidos sobre esta norma fueron muy variados y de toda índole; destacaron fundamentalmente los siguientes: en relación con la primera conexión, se indicaba a favor de su consagración que fue un criterio aplicado por la jurisprudencia del Tribunal Supremo durante el corto período de vigencia de la Ley del divorcio de 2 de marzo de 1932, la cual no establecía normas de Derecho internacional privado en esta materia, además de ser fiel al artículo 9.1 del Código civil que declara aplicable la ley nacional al Estado civil y a los derechos y deberes de familia ${ }^{1}$. Asimismo, se argumentaba que, con esta conexión, se respetaba el carácter

${ }^{1}$ EsPinar Vicente, J. M., «Normas de Derecho internacional privado», Comentarios a las reformas del derecho de familia, Madrid 1984, p. 758. 
multicultural de nuestra sociedad y que era sumamente eficaz y respetuoso con el principio de proximidad cuando los cónyuges se sentían vinculados estrechamente con su Estado de origen, teniendo la intención de permanecer en nuestro Estado por un tiempo determinado, pero siempre poniendo sus miras en el futuro y pronto regreso a su Estado de procedencia; sin embargo, entre los inconvenientes se aducía, el llamado por J. D. González Campos efecto bloqueante ${ }^{2}$, sobre la siguiente ley aplicable, que era la residencia habitual del matrimonio, la cual podía constituir el centro de vida real de la pareja cuando aquella había configurado un proyecto de vida en común en nuestro territorio y más teniendo en cuenta la actual situación que nuestro país está viviendo al convertirse de un país exportador de emigrantes, en un Estado receptor de éstos, de manera que a estas personas que tenían la intención de vivir de una forma estable en nuestro territorio se le imponía la aplicación de una ley que, a todas luces, resultaba ya ajena a su relación ${ }^{3}$.

La conexión de la residencia habitual fue generalmente bien aceptada y valorada por la doctrina, ya que, en defecto de nacionalidad común, ha constituido una de las orientaciones recogidas en nuestro Código civil a partir de la reforma del Título Preliminar operada en 1974. Su aplicación en materia de separación judicial y divorcio se justificaba por constituir un criterio de regulación neutral, al no preferir la ley personal de uno u otro cónyuge y, por tanto, evitar cualquier discriminación por razón de sexo. Además nos situaba en el lugar en que los cónyuges tienen su centro de vida familiar al solicitar el divorcio, lo cual conllevaba la obtención de un resultado fácilmente previsible ${ }^{4}$. No obstante, resultaba cuestionable que el precepto no concretara el momento de su apreciación por el aplicador del Derecho, lo que dio lugar a varias interpretaciones, entre las que destacan, en primer lugar, aquella que mantenía que por analogía con la primera conexión utilizada, la residencia habitual común del matrimonio tenía que considerarse en el momen-

${ }^{2}$ González Campos, J. D., «Derecho de familia. El matrimonio», AA.VV., en Derecho internacional privado. Parte especial, Madrid, 1995, p. 322.

${ }^{3}$ En relación con estas ventajas e inconvenientes, Vid. con carácter general, BLANCOMorales Limones, P., «Crisis matrimoniales», AA.VV., en Derecho internacional privado. Vol. II, Granada, 2003, p. 150. PALAu Moreno, G., «La separación y el divorcio de extranjeros en España: entre su integración y el respeto de su identidad cultural», Rev. Actualidad Civil, 2001, num. 15, p. 559. EsPlugues MotA, C., El divorcio internacional (jurisdicción, ley aplicable, reconocimiento y ejecución de sentencias extranjeras), Valencia, 2003, p. 115. Carrascosa González, J., Matrimonio y elección de ley. Estudio de Derecho internacional privado, Granada, 2000, pp. 188 y ss.

${ }^{4}$ Vid., entre otros, Aguilar Benítez De Lugo, M., «La ley aplicable al divorcio en el Derecho internacional privado español», Boletín de Información del Ministerio de Justicia, num. 1566, p. 2631. ABARCA JunCO, P., «Separación matrimonial y disolución del matrimonio», en Derecho internacional privado, Vol. II, Coord. por E. Pérez Vera, UNED, Madrid 2001, p. 152. 
to de la presentación de la demanda ${ }^{5}$ y, en segundo lugar, la que sostenía que, habida cuenta de que no se especificaba la apreciación temporal de esta conexión, ésta se podría tener presente en cualquier momento de la vida del matrimonio ${ }^{6}$.

Por último, la utilización de la ley española como lex civilis fori se justificaba desde el momento en que a falta de las conexiones anteriores y, dado que nuestros tribunales eran competentes, a tenor del artículo 22.3 de la Ley Orgánica del Poder Judicial, ninguna ley mejor que la española para ser aplicada a la separación o al divorcio. El que la ley española recoja cuándo ha de ser constatada la existencia de la ley aplicable, evitaba que, por la voluntad unilateral de alguno de los cónyuges, se alterara la ley aplicable a la separación o al divorcio ${ }^{7}$. No obstante y, a pesar de esta ventaja, esta solución fue criticada por su simplismo y porque, en los últimos tiempos, a raíz de la entrada en vigor del Reglamento Comunitario 1347/2000 de 29 de mayo relativo a la competencia, el reconocimiento y la ejecución de resoluciones judiciales en materia matrimonial y de responsabilidad parental sobre los hijos comunes ${ }^{8}$, los foros de competencia judicial internacional en esta materia se habían ampliado considerablemente, de manera que la ley española resultaba aplicable a numerosos supuestos ${ }^{9}$.

\section{LA REFORMA DEL ARTÍCULO 107.2 DEL CÓDIGO CIVIL}

\section{Iniciativa de la reforma legislativa}

No obstante todos estos argumentos, la doctrina siempre manifestó la necesidad de que este precepto contemplara la posibilidad de que las partes se pudieran divorciar o separar con arreglo a la ley española cuando su ley nacional común no admitiera esta posibilidad, y así lo puso de relieve una enmienda realizada al Proyecto de Ley por el Grupo Parlamentario Comunista, por la que se proponía que se aplicara el Derecho español en el caso en que el Derecho extranjero designado por la norma de conflicto no contemplase el divorcio, si bien en casos conectados estrechamente con el Orde-

\footnotetext{
5 Amores Conradi, M., «Artículo 107», en Comentarios al Código Civil, Centro de Publicaciones del Ministerio de Justicia, Madrid, 1991, pp. 425 y ss.

${ }^{6}$ Blanco-Morales Limones, P. «Crisis matrimoniales», Ob. cit., p. 124.

${ }^{7}$ ESPINAR ViCENTE, J. M. El matrimonio y las familias en el sistema español de Derecho internacional privado, Madrid, 1999, pp. 195-199.

${ }^{8}$ Doce L 160 de 30 de junio de 2000. En este mismo Diario existe un informe explicativo realizado por BORRÁs RoDRIGUEZ, A., pp. 27 y ss. Actualmente este Reglamento ha sido sustituido por el Reglamento 2201/2003 del Consejo de 27 de noviembre, al cual nos referiremos más adelante.

${ }^{9}$ ESPINAR VICENTE, J. M., «Normas de Derecho internacional privado», en Comentarios a las reformas del derecho de familia, Madrid, 1994, p. 759.
} 
namiento español, que no prosperó ${ }^{10} ;$ sin embargo, en ningún momento se ha observado por el legislador la necesidad de modificar la norma ${ }^{11}$. Han sido los propios tribunales los que han tenido que valerse de ciertos recursos jurídicos para proceder a declarar el divorcio o la separación judicial de parejas cuya ley nacional común no admitía estas figuras sobre la base de la no alegación y prueba por las partes del Derecho extranjero aplicable al fondo del asunto $^{12}$, de manera que, a la luz de la reiterada doctrina del Tribunal Supremo, ante tal situación deberá juzgarse y fallarse según el Derecho material español ${ }^{13}$ como lex fori, pero nunca desestimar la demanda propiciando un non liques ${ }^{14}$. Ello se deduce del artículo 281.2 de la Ley de Enjuiciamiento

${ }^{10}$ Esta enmienda rezaba del siguiente modo: «No obstante, si la ley extranjera aplicable conforme a lo dispuesto en el párrafo anterior, no admite la disolución de matrimonio por divorcio, se aplicará la ley española si uno de los cónyuges es español y tiene su residencia habitual en España». Vid. GonzÁlez CAmpos, J. D. y ABARCa Junco, P., «Matrimonio y divorcio», en Comentarios al nuevo Título IV del Libro Primero del Código civil, Madrid, 1990, p. 910.

${ }^{11}$ Así, en la reforma operada al Código civil por la Ley 11/1990 de 15 de octubre en materia de no discriminación por razón de sexo, este precepto no gozó de modificación alguna en el sentido apuntado, a pesar de que la reforma operada en el artículo 9.3 consagró la autonomía de las partes para elegir la ley aplicable a sus capitulaciones matrimoniales. Vid. en torno a esta disfunción, ZABALO ESCUDERO, E., «Efectos del matrimonio y sociedad multicultural», AA.VV., en Estatuto personal y multiculturalidad de la familia, Dir. por A.L. Calvo Caravaca y J. Carrascosa González, Madrid, 2000, pp. 21-25.

${ }^{12}$ Pionera en seguir esta línea fue la sentencia del Juzgado de Primera Instancia de Mieres de 28 de diciembre de 1981, en relación con dos cónyuges que eran de nacionalidad española y que, posteriormente al amparo del Convenio de doble nacionalidad de 28 de mayo de 1958, adquirieron la nacionalidad chilena y, tras volver a España, no inscribieron su domicilio en el Registro español, de manera que, a tenor del mencionado Convenio, subsistía la nacionalidad chilena como nacionalidad efectiva, de tal forma que, al no conocer el divorcio el Derecho chileno, ley aplicable por los tribunales como ley nacional común de los cónyuges en el momento de la presentación de la demanda de divorcio, tal divorcio debería ser denegado por el Juzgado de Primera Instancia. Ante tal situación, el órgano jurisdiccional declaró no probado por las partes el Derecho chileno y, aplicando el Derecho sustantivo español decretó el divorcio de las partes. La Audiencia Territorial de Oviedo, en su sentencia de 20 de octubre de 1982 revocó la sentencia del Juzgado al indicar que esta situación no se hubiera producido si se hubiera aceptado la enmienda al Proyecto de ley que proponía la aplicación del Derecho español en el caso en que el derecho extranjero reclamado por la norma de conflicto desconociera el divorcio.

${ }^{13}$ Sentencias del Tribunal Supremo de 15 de marzo de 1984, 7 de septiembre de 1990 y 13 de diciembre de 2000.

${ }^{14}$ Así, el Tribunal Supremo, en su sentencia de 5 de marzo de 2002 manifiesta que «... evidentemente el contenido de las normas sustantivas aplicables de dicha Ley (sea la británica, la ghanesa o cualquier otra distinta de la española) no ha sido acreditado por ninguna de las partes, como afirma el Tribunal de instancia, por lo que según esta Sala ha establecido reiteradamente (Sentencias de 7 de septiembre de 1990 y 11 de mayo de 1989, entre otras muchas y, más recientemente la de 13 de diciembre de 2000) procede resolver la cuestión debatida conforme a las normas de nuestro propio ordenamiento jurídico...». 
Civil que, en sustitución del artículo 12.6 párrafo $2 .^{\circ}$ del Cc. ${ }^{15}$, indica que «el derecho extranjero deberá ser probado en lo que respecta a su contenido y vigencia», añadiendo que el juzgador podrá valerse de «cuantos medios de averiguación estime necesarios» ${ }^{16}$. Así pues, ante la pregunta formulada a diversos magistrados acerca de si se ha de desestimar la demanda en los procesos de separación y divorcio si la ley extranjera aplicable al caso no fuese alegada y probada por las partes, la práctica totalidad de los encuestados han contestado de forma negativa al indicar que, lejos de la desestimación, lo correcto es la aplicación el Derecho material español ${ }^{17}$. Esta solución es la que adopta la sentencia de la Audiencia Provincial de Murcia de 12 de mayo de 2003 al considerar que el Derecho marroquí, como ley nacional común de las partes aplicable al divorcio, no ha sido alegado ni probado por las partes, de manera que procede la aplicación del Derecho español. A mayor abundamiento, la esposa demandante expresa su consideración de que si se aplicara este Derecho vulneraría el orden público internacional español al ser discriminatorio para la mujer. Así, la esposa alega el Derecho extranjero, pero lo hace de una forma negativa al manifestar su oposición con el orden público internacional español ${ }^{18}$.

Otra de las posibles soluciones que se había mencionado por la doctrina es el posible reenvío que la ley nacional común, como ley rectora del divorcio, pudiera realizar a la norma española como ley del lugar de la residencia habitual del matrimonio ${ }^{19}$.

${ }^{15}$ Derogado por la Disposición Derogatoria Única de la Ley 1/2000 de 7 de enero de Enjuiciamiento Civil, BOE, 8 de enero de 2000.

${ }^{16}$ La interpretación que el Tribunal Constitucional ha efectuado de este precepto (art. 12.6 pfo. $2^{\circ}$ ) en su sentencia 10/2000 de 17 de enero, es que las partes han de introducir en el proceso el Derecho extranjero, pero no cabe la pasividad del juzgador en cuanto a la investigación y determinación de su vigencia. De esta forma, el Alto Tribunal mantiene que a la luz del artículo 24 de la Constitución «... la decisión deberá adoptarse siempre condicionada por la obligación del órgano judicial de prestar a las partes en el proceso judicial del que conozca una efectiva tutela de sus derechos e intereses legítimos, en particular cuando la aplicación del Derecho extranjero resulta debida por la imposición del propio ordenamiento jurídico español y como consecuencia de lo alegado por las partes en el litigio. En efecto, en supuestos como éste y, teniendo en cuenta sus singulares circunstancias, la acreditación del Derecho extranjero y la intervención del órgano judicial en su prueba puede trascender de la mera valoración de la prueba de un hecho alegado por la parte en apoyo de sus pretensiones, que indudablemente es competencia exclusiva de los órganos judiciales ordinarios».

${ }^{17}$ Vid. encuesta realizada por P. GonZÁLEZ VicENTE en Revista Sepin-Familia, num. 28 de 2003, pp. 9-23.

${ }^{18}$ Vid. el interesante comentario realizado a esta sentencia por RodRÍGUEZ RodRIGO, J., «Crisis matrimoniales: foro de necesidad en relación con la sentencia num. 166/2003», AA.VV., en El derecho de familia ante el siglo XXI: aspectos internacionales, Dir. por A.L. Calvo Caravaca y E. Castellanos Ruiz, Madrid, 2004, pp. 705-721.

${ }^{19}$ GonZÁlez CAmpos, J. D., «Derecho de familia. El matrimonio», AA.VV., en Derecho internacional privado, Ob. cit. p. 323. 
No obstante, todas estas soluciones se han tomado de forma nada coordinada, y la resolución judicial a favor o no de la declaración de la separación o el divorcio dependía del tribunal que conociera del asunto, lo cual conllevaba una gran inseguridad jurídica. Ha sido a raíz de una recomendación elevada por el Defensor del Pueblo al Ministerio de Justicia cuando el artículo 107 del Código civil ha gozado de una modificación largamente esperada, ya que cuando este precepto vio la luz en el año 1981, España no tenía todavía el número de inmigrantes que tiene hoy ni, por lo tanto, se habían presentado ante nuestros tribunales las cuestiones que se están planteando hoy en día.

La recomendación del Defensor del Pueblo mencionada tiene su base en una queja formulada por una nacional marroquí residente legal en España casada con un marroquí y con un hijo de siete años habido del matrimonio, que tuvo que abandonar el domicilio conyugal con su hijo debido a las desavenencias y a los malos tratos propiciados por su marido. La interesada solicitó la adopción de medidas provisionalísimas ante el Juzgado de Primera Instancia de Murcia, las cuales fueron aprobadas mediante auto de 21 de diciembre de 2001, en el cual se señalaba que éstas quedarían sin efecto si en el plazo de 30 días no se presentaba la oportuna demanda ante el juez o tribunal competente ${ }^{20}$. El abogado de la interesada se puso en contacto con el Defensor del Pueblo para manifestarle que, de acuerdo con el artículo 107 del Código civil, la separación y el divorcio se regirían por la ley nacional común de los cónyuges al tiempo de la presentación de la demanda, dándose el caso de que la ley marroquí, como ley nacional común, no contempla la figura legal de la separación, sino sólo el divorcio y el repudio por voluntad unilateral del marido ${ }^{21}$. De acuerdo con esta ley, la mujer no puede repu-

${ }^{20}$ La Ley 27/2003 de 31 de julio regula la orden de protección de las víctimas de la violencia doméstica (BOE num. 183 de 1 de agoto de 2003), por medio de la cual, el juez adoptará las medidas precisas de carácter penal y civil con la finalidad de proteger a la víctima; éstas tendrán una duración de treinta días, quedando sin efecto si la solicitante no interpone en este periodo de tiempo la oportuna demanda.

${ }^{21}$ El procedimiento que entonces regía en Marruecos para repudiar a la esposa era relativamente simple y relativamente rápido, aunque en un primer momento se complique a consecuencia de su carácter revocable, pues algunos ordenamientos islámicos exigen la existencia de un acto previo de conciliación. En el Derecho marroquí el repudio tenía que ser firmado por dos notarios (adules) bajo la jurisdicción del juez del domicilio conyugal. Tenía que ser registrado en presencia de ambas partes tras la autorización del juez. Si la esposa no comparecía, no era motivo para no seguir adelante con el repudio si el marido permanecía en su actitud. Sin embargo, para dar publicidad al acto del repudio, se preveía que el juez informara a la mujer de su nueva situación desde que se pronunciaba el repudio y le hiciera llegar su acta original cuya propiedad ostentaba, en un plazo no superior a quince días, mientras que al marido se le entregaba una copia. Las formalidades del repudio se establecían en los artículos 80 y 81 del Código marroquí, y se señalaba a tal efecto que en el acta había de constar si es el primer, segundo o tercer repudio. Este requisito es de suma importancia, ya que indicaba si el repudio era revocable o no, de manera que 
diar al marido y, para obtener el divorcio en contra de la voluntad del marido, deberá litigar por un periodo de tiempo excesivamente amplio, unos cinco años como mínimo, mientras que si es el marido el que lo solicita el tiempo en el que se dicta la resolución se reduce considerablemente, unos quince días ${ }^{22}$. Así las cosas, el Defensor del Pueblo se informa de la veracidad de

en el acta constaba la disolución definitiva del matrimonio. Ello es así, desde el momento en que en los sistemas islámicos, por regla general, admiten dos tipos de repudio: el revocable y el irrevocable. El primero tiene lugar cuando es temporal o limitado en el tiempo, a fin de que el esposo reflexione acerca de la decisión que ha tomado; la mujer debe quedar en ese periodo de tiempo en una situación de retiro legal (idda), que dura tres meses, o se amplía a diez si está embarazada, para que no existan dudas acerca de la paternidad del marido, de manera que el matrimonio subsiste a todos los efectos legales (arts. 58 y 60 del Código argelino). Es el marido el que decide dónde va a cumplir la mujer su retiro legal, y no se tiene en cuenta para nada la opinión de ésta, de manera que si no cumple con esta obligación del retiro se considera que ha abandonado el domicilio conyugal. Si el marido se retracta de su decisión antes de que transcurra el plazo de la idda, el matrimonio reanuda su vida conyugal sin que la esposa tenga que mostrar su conformidad. Si esta situación tiene lugar, el marido tiene el privilegio de pronunciar un segundo repudio, así hasta tres veces, momento en el cual el repudio se transforma en irrevocable. También adquiere esta cualidad cuando el marido deja pasar el periodo de la idda sin deponer su actitud. Nótese que en ningún caso se tiene en cuenta para nada la opinión de la mujer, que está sujeta en todo momento a la voluntad de su marido.

En cuanto a los efectos del repudio, también eran bastante discriminatorios en relación con la mujer, ya que ésta, aunque conservaba la guarda y custodia de los hijos (hadana), hasta que éstos adquieren cierta edad dependiendo del sexo, la patria potestad la ostentaba el padre con todos los privilegios que ello conlleva. La hadana se perdía, entre otras causas, si la mujer contraía nuevas nupcias, o si fijaba su residencia en un lugar no permitido por el padre o si educba a los hijos en una religión que no fuera la musulmana, independientemente de que la madre la profesara o no.

En relación con los efectos económicos, recientemente se ha articulado en algunos países, Marruecos entre ellos, que se establezca una compensación económica para la mujer por los perjuicios ocasionados, si bien en la práctica, ésta suele ser de escasa cuantía; todo depende de la posición social que hubiera tenido el matrimonio. Aunque la mujer conserve la guarda de los hijos, no tiene derecho a permanecer en el domicilio conyugal, a no ser que sea de su propiedad. Como consecuencia del repudio, el marido ha de abonar la parte de dote correspondiente según se hubiera pactado en el contrato matrimonial.

${ }^{22}$ En relación con el repudio, Vid. con carácter general, ADAM MuÑOZ, M. D., La protección de los derechos de las mujeres en una sociedad multicultural, Córdoba, 2001. ADROER BioscA, S., «Matrimonio islámico y Derecho internacional privado español», AA.VV., en Hominum causa omne ius constitutum est. Escritos sobre el matrimonio en homenaje al Prof. J. M. Díaz Moreno, Madrid, 2000, pp. 889-890. Palau Moreno, G., «La separación y el divorcio de extranjeros en España: entre su integración y el respeto de su identidad cultural», Rev. Actualidad Civil, 2001, num. 15, p. 559. Aguilar BeníteZ De Lugo, M., «Estatuto personal y orden público en un contexto de creciente multiculturalidad», en Las minorías en una sociedad democrática y pluricultural. Ed. I. García Rodríguez, Alcalá de Henares, 2001, p. 333. Aguilar GRIEDER, H., «Multiculturalidad, reconocimiento en España de repudios islámicos pronunciados en el extranjero y actuales tendencias del orden público en DIPr.», AA.VV., en Cuestiones actuales de derecho comparado, Dir. por G. Morán García, 
la situación y de que la práctica de nuestros tribunales es confusa, de manera que, para evitar estas situaciones claramente discriminatorias para la mujer, recomienda al Ministerio de Justicia que modifique el artículo 107 del Código civil de tal manera, que contemple la posibilidad de que, a elección de la parte demandante, la separación o el divorcio puedan regirse también por la ley española y no exclusivamente por la ley nacional común de los cónyuges cuando ambos residan en España ${ }^{23}$.

La Coruña, 2003, pp. 235 y ss. CARLIER, J. Y., «La reconnaissace en Belgique des répudiations unilatérales intervenues ou Maroc», Journal del Tribunaux, 1985, pp. 102-115. Id., «Volonté ordre public et fraude dans la reconnaissance des divorces et répudiations intervenus à l'étranger», Revue trimestrale de droit familial, 1991 (II), pp. 165-172. CARRASCOSA GonzÁlez, J., «Crisis matrimoniales y dispersión del pleito», AA.VV., en Globalización y derecho, Dir. por A.L. Calvo Caravaca y J. Carrascosa González. Madrid 2003. Id. Matrimonio y elección de ley estudio de Derecho internacional privado, Granada, 2000, esp. pp. 40-120. DePREZ, J., «Droit international privé et conflicts de civilisations. Aspects méthodologiques. Les relations entre systèmes d'Europe occidentale et systèmes islamiques en matière de statut personnel», Recueil des Cour, t. 211, 1988/IV, pp. 200-216. Id. «Statut personnel et practiques familiares des étrangers musulmans en France. Aspects de Droit international privé», en Familles-Islam-Europe, Dir. por M. C. Foblets, París, 1996, pp. 9498. Id. «Droit internacional privé et conflicts de civilisation». EsPlugues Mota, C., El divorcio internacional (jurisdicción, ley aplicable, reconocimiento y ejecución de sentencias extranjeras, Valencia, 2003, pp. 90-94. FADLALLAH, I., «Vers la reconnaissance de la rèpudiation musulmana par le juge français?», Revue Critique de droit international, 1981, pp. 17-34. FobleETS, M. C., «Conflits conjugaux et inmigration. Libérer la femme marocaine musulmane malgré elle?», Annales de Droit de Louvain, 1999, pp. 66-68. Hamme, P., «Effects en France des repudiations musulmanes; fraude et ordre public», en Droit de l'enfance et de la familla, 1996, pp. 106-112. LAGARDE, P., «La thèorie de l'ordre public international face à la polygamie et à la repudiation. l'expérience française», en Nouveaux itinéraires en droit, Homenage a F. Rigaux. Bruselas, 1993, p. 276. MERNISSI, S, «El estatuto de la mujer en Marruecos», AA.VV., en el Islam jurídico y Europa, Dir. por A. BorRÁs RodRíGUEZ y S. MERNISSI, Barcelona, 1997, pp. 106-107. MonÉGER, F., «Vers la fin de la reconnaissance des rèpudiations musulmanes par le juge français?», en Journal Clunet de droit international, 1992, pp. 347-355. QuIÑONES ESCAMEZ, A., «Limitaciones infundadas al ius nubendi: el repudio revocable. En torno a la Resolución de la DGRN de 4 de junio de 2001, sobre autorización del matrimonio civil», en Derecho registral internacional. Homenaje al Prof. R. Arroyo Montero, Madrid, 2003. Id. «La disolución del matrimonio: especial referencia al repudio islámico», en La multiculturalidad: especial referencia al Islam, Cuadernos de Derecho judicial, VIII-2002, pp. 280-281. Id. Derecho e inmigración: el repudio islámico en Europa, Barcelona, 2000.

${ }^{23}$ Agradezco muy sinceramente la información facilitada por la Oficina del Defensor del Pueblo y el envío de la mencionada recomendación, en particular, al asesor de «Justicia y Violencia doméstica». 


\section{La respuesta legislativa a la demanda realizada por el Defensor del Pueblo}

No obstante la concreta indicación realizada en la recomendación por el Defensor del Pueblo al Ministerio de Justicia, el legislador ha efectuado una reforma mucho más amplia, e incluso distinta, que la sugerida por éste que se circunscribía a que la Ley posibilitara el ejercicio de la autonomía de la voluntad por las partes (en concreto, la parte demandante) limitada a elección, bien de la ley de la nacionalidad común o bien la ley de la residencia habitual común cuando ésta radicara en España ${ }^{24}$, de manera que así se propiciaba que los cónyuges pudieran aplicar tanto la ley del país de acogida (ley española), en el caso en que desearan su integración, como la ley del Estado de origen, en el supuesto en que su proyecto se dirigiera a regresar allí conservando la tradición de su país ${ }^{25}$.

La reforma fue operada por la Ley Orgánica 11/2003 de 29 de septiembre de Medidas concretas en materia de seguridad ciudadana, violencia doméstica e integración social de los extranjeros ${ }^{26}$, lo que fue criticado por cierto sector doctrinal al entender que éste no era el lugar más adecuado para efectuar la modificación, toda vez que la Ley Orgánica aborda fundamentalmente medidas de carácter penal de manera que no resulta adecuada la asociación que la Ley establece entre el Plan de Lucha contra la Delincuencia y las medidas necesarias para la integración social de los extranjeros en España $^{27}$. Por otra parte, se ha argumentado que la ubicación de esta norma no es la más adecuada, ya que hubiera sido preferible colocarla al final del artículo 9.2 del Código civil, que regula la ley aplicable a los efectos del matrimonio, cuando éste hace referencia en su inciso final al artículo 107 del Código civil. De esta forma, se hubiera reubicado junto al resto de los preceptos

\footnotetext{
${ }^{24}$ Textualmente la recomendación indica lo siguiente: «... ese Ministerio de Justicia pueda promover las reformas legislativas necesarias tendentes a la modificación del artículo 107 del Código civil, de tal manera que contemple la posibilidad de que, a elección de la parte demandante, la separación o el divorcio pueda regirse también por la ley española y no exclusivamente por la ley nacional común cuando ambos cónyuges residan habitualmente en España».

${ }^{25}$ Estos extremos han sido puestos de manifiesto por A. L. Calvo Caravaca y J. CARrascosa GonZÁlez, «Crisis matrimoniales», en Derecho internacional privado, Granada, 1998, p. 157.

${ }^{26}$ BOE num. 234 de 30 de septiembre de 2003. El 21 de marzo de 2003 fue publicado en el BOCGCD el proyecto de Ley Orgánica de esta Ley, la cual se ha sometido a una tramitación muy urgente, de manera que el texto fue aprobado en el Senado el 18 de septiembre sin que sufriera modificación alguna sobre el original, ya que no aceptaron ninguna de las enmiendas realizadas al texto.

${ }^{27}$ Campuzano DíAz, B., «Consideraciones acerca de la reforma del art. 107 del Código civil», AA.VV., en El derecho de familia ante el siglo XXI: aspectos internacionales, Dir. por A. L. Calvo Caravaca y E. Castellanos Ruiz. Madrid 2004, pp. 183-184.
} 
de Derecho internacional privado dedicados a los efectos del matrimonio, lográndose así una más lógica ordenación legislativa ${ }^{28}$.

\section{CONTENIDO DE LA REFORMA LEGISLATIVA: ANÁLISIS DE LOS DIFERENTES SUPUESTOS RECOGIDOS EN EL ARTÍCU- LO 107}

El párrafo segundo del artículo 107 del Código civil establece la ley aplicable a la separación judicial y el divorcio, indicando al respecto esto: « $L a$ separación y el divorcio se regirán por la ley nacional común de los cónyuges en el momento de la presentación de la demanda; a falta de nacionalidad común, por la ley de la residencia habitual común del matrimonio en dicho momento y, en defecto de ésta, por la ley de la última residencia habitual común del matrimonio si uno de los cónyuges aún reside habitualmente en dicho Estado.

En todo caso, se aplicará la ley española cuando uno de los cónyuges sea español o resida habitualmente en España: a) Si no resulta aplicable ninguna de las leyes anteriormente mencionadas. b) Si en la demanda presentada ante el tribunal español la separación o el divorcio se pide por ambos cónyuges o por uno con el consentimiento del otro. c) Si las leyes indicadas en el párrafo primero de este apartado no reconocieran la separación o el divorcio o lo hicieran de una forma discriminatoria o contraria al orden público».

De la redacción de este precepto se desprende que éste se divide en dos partes bien diferenciadas: la primera de ellas constituye una norma de conflicto bilateral en la que se establecen diversos puntos de conexión en cascada o de forma jerarquizada que determinan la ley aplicable a estas dos instituciones: la separación judicial y el divorcio; y, en segundo lugar, nos encontramos con una norma de extensión o autolimitada, la cual aplica la ley española a la separación judicial y al divorcio en aquellos supuestos en los que la relación está estrechamente vinculada con el Ordenamiento español, como sucede en los casos en que uno de los cónyuges sea español o resida habitualmente en España, si bien, no establece el momento en el que el aplicador del Derecho ha de tener en cuenta estas circunstancias, de manera que, siguiendo un criterio interpretativo análogo con el párrafo primero, podemos concluir que éstas habrán de ser observadas en el momento de la interposición de la demanda. En las líneas que siguen vamos a proceder al análisis de estos dos párrafos:

${ }^{28}$ Diago Diago, M. P., «La nueva regulación española de las crisis matrimoniales ante el impacto de la multiculturalidad», AA.VV., en El derecho de familia ante el siglo XXI: aspectos internacionales, Dir. por A. L. Calvo Caravaca y E. Castellanos Ruiz, Madrid, 2004, pp. 277-278. 


\section{El inciso primero del artículo 107.2 del Código civil: conexiones utili- zadas}

Este inciso señala que la separación y el divorcio se regirán por la ley nacional común de los cónyuges en el momento de la presentación de la demanda; a falta de nacionalidad común, por la ley de la residencia habitual común del matrimonio en dicho momento y, en defecto de ésta, por la ley de la última residencia habitual común del matrimonio si uno de los cónyuges aún reside habitualmente en dicho Estado.

Como podemos comprobar, se sigue manteniendo la aplicación de la ley nacional común del matrimonio concretada en el momento de la presentación de la demanda, de manera que, a través de la aplicación de esta ley, se posibilita el respeto a la identidad cultural de aquellas personas que residan de forma temporal en España y que no se encuentran arraigadas plenamente en nuestro Estado, sino que su intención es regresar algún día a su país de origen. Con la aplicación de esta ley se asegura que los implicados no van a tener excesivas dificultades para que la resolución dictada por los tribunales españoles sea reconocida en su país de origen.

El momento de la determinación de la ley nacional común, a mi juicio, también resulta adecuado, toda vez que, en numerosas ocasiones, en el tráfico externo, los matrimonios cuando se celebran suelen ser mixtos; es decir, las partes tiene diferente nacionalidad, prueba de lo cual es que nuestro sistema establece un periodo de residencia legal y continuada en España sensiblemente inferior a la vía ordinaria para que la persona extranjera que esté casada con español o española pueda adquirir la nacionalidad española ${ }^{29}$. Así pues, si la nacionalidad diferente de las partes es normal al comienzo del matrimonio, sucede en bastantes casos que en el momento de la disolución es la misma.

Asimismo, se sigue manteniendo el criterio de la residencia habitual común del matrimonio, si bien el legislador ya sí establece el momento en que ésta ha de ser apreciada; es el momento de la interposición de la demanda, criterio que anteriormente se seguía por analogía con la determinación del momento en el que el precepto establecía que se había de apreciar la ley nacional común del matrimonio.

Por último, el precepto abandona la aplicación de la ley española como lex civilis fori y establece la conexión de la última ley de la residencia habi-

${ }^{29} \mathrm{El}$ artículo $22.2 d$ del Código civil señala que bastará un tiempo de residencia en España de un año para solicitar la nacionalidad española si en el momento de la solicitud estuviere casada con español o española y no estuviere separado legalmente o de hecho, mientras que, en todos los demás casos se requiere que el tiempo de residencia por un periodo de diez años, o de cinco en los supuestos en los que se haya obtenido asilo o refugio o de dos años cuando se trate de nacionales de origen iberoamericano, Andorra, Filipinas, Guinea Ecuatorial, Portugal o de sefardíes. 
tual común del matrimonio si uno de los cónyuges, da igual que sea el demandante o el demandado, aún reside habitualmente en dicho Estado ${ }^{30}$. La intención que subyace en el establecimiento de este criterio es la de aplicar una ley con la que el matrimonio haya estado vinculado, corrigiendo aquellas situaciones en las que el matrimonio de distinta nacionalidad, pero con residencia habitual común en un Estado determinado, se ha roto o está en vías de ruptura, dando lugar a que las partes se separen de hecho y que una de ellas abandone el país en el que el matrimonio ha tenido su última residencia habitual común. En el momento de la interposición de la demanda, habida cuenta de que ha existido una separación de hecho, las partes no tendrían una residencia habitual común, de manera que sería imposible aplicar esta ley a la separación o al divorcio. Así pues, el legislador ha considerado que la ley de la última residencia habitual común, si uno de los cónyuges aún reside en ese Estado, refleja fielmente la proximidad que el matrimonio ha poseído con un determinado Ordenamiento, de manera que, para poder aplicar ésta ha mantenido el criterio de la residencia habitual de, al menos, uno de los cónyuges, en el lugar en el que el matrimonio tuvo su última residencia habitual común.

Lógicamente, esta ley no tendrá que coincidir con la ley española, ya que puede darse el caso, por ejemplo, de un matrimonio entre español y francesa que residían habitualmente en Francia y que, ante la ruptura de hecho de su matrimonio, el cónyuge español regrese a España e interponga ante los tribunales españoles la demanda de divorcio de mutuo acuerdo. Así las cosas y, ya que su cónyuge reside de manera habitual en Francia y éste ha sido el lugar de la última residencia habitual del matrimonio, podrá ser la ley francesa la que se aplique al fondo del divorcio, aunque sean competentes los tribunales españoles para conocerlo.

No obstante lo anterior, la determinación de la ley aplicable coincide con uno de los presupuestos de la competencia judicial internacional de los tribunales españoles señalada en el Reglamento Comunitario 2201/2003 del Consejo de 27 de noviembre de 2003, relativo a la competencia, el reconocimiento y la ejecución de las resoluciones judiciales en materia matrimonial y de responsabilidad parental ${ }^{31}$, ya que, a tenor de su artículo 3, los tribunales españoles serán competentes si España ha sido el último lugar de la residencia habitual común del matrimonio y uno de los cónyuges aún reside en nuestro Estado. De esta forma, se trata de evitar que, ante la inminente ruptura de un matrimonio de extranjeros de distinta nacionalidad, cuya última residencia habitual común ha sido España y, una vez que uno de los cónyu-

${ }^{30}$ La residencia habitual se entiende como «centro social de vida del cónyuge». A tal efecto, no importa que la residencia sea legal o ilegal, SAP de Cuenca de 26 de febrero de 2004.

${ }^{31}$ DOUE num. L 338, de 23 de diciembre de 2003. 
ges ha interpuesto demanda de separación o divorcio ante los tribunales españoles, el otro cónyuge regrese a su país de origen e interponga ante los tribunales de su Estado demanda de separación o divorcio esperando lograr una resolución más favorable a sus pretensiones, y se oponga a la demanda interpuesta ante los tribunales españoles alegando litispendencia o la existencia de una sentencia judicial firme extranjera entre las mismas partes y sobre la misma causa ${ }^{32}$.

\section{Segundo inciso del artículo 107.2 del Código civil: conexiones utiliza- das}

Independientemente de las leyes establecidas en el párrafo primero, las cuales se siguen aplicando de forma jerarquizada o en cascada, será de aplicación la ley española siempre que uno de los cónyuges sea español o resida habitualmente en España en los siguientes casos:

a) si no resultara aplicable ninguna de las leyes anteriormente mencionadas,

b) si en la demanda presentada ante tribunal español la separación o el divorcio se pide por ambos cónyuges o por uno con el consentimiento del otro y

c) si las leyes indicadas en el párrafo primero de este apartado no reconocieran la separación o el divorcio o lo hicieran de forma discriminatoria o contraria al orden público.

Los criterios utilizados por el legislador español para proceder, en todo caso, a la aplicación de la ley española son los mismos que se establecen en el Reglamento Comunitario 2201/2003 del Consejo de 27 de noviembre de 2003 , relativo a la competencia, el reconocimiento y la ejecución de las resoluciones judiciales en materia matrimonial y de responsabilidad parental; es decir, la aplicación de la normativa española se sustenta sobre la base de la residencia habitual en España o de la nacionalidad española de alguno de los cónyuges, de manera que nuestra normativa regirá la separación o el divorcio en no pocas ocasiones. Ahora bien, estos extremos se tendrán en cuenta

\footnotetext{
${ }^{32}$ Así, la sentencia de la AP de Murcia de 9 de marzo de 2007 (sección 5.a) (Aranzadi Wetlaw JUR/2007/264859), ante la alegación de la parte demandada de que existe una sentencia de divorcio dictada por los tribunales marroquíes y el requerimiento por el tribunal para que presente una copia certificada, estima que tal proceso de divorcio seguido en Marruecos se inició con posterioridad al proceso de separación judicial iniciado ante los tribunales españoles por la demandante, de manera que, como indica el artículo 410 de la LECv, la litispendencia, con todos sus efectos procesales, se produce desde el momento de la interposición de la demanda si después ésta es admitida, como sucede en el caso que se está juzgando. Anteriormente y, en el mismo sentido, Sentencia de la AP de Murcia de 12 de mayo de 2003 (sección 1. ${ }^{\text {) }}$ (Aranzadi Wetlaw AC/2003/1676).
} 
de forma cumulativa con los supuestos establecidos a continuación, si bien éstos juegan de una forma alternativa; es decir, basta con que se dé uno de ellos para que la ley española sea de aplicación.

a) El primer supuesto; es decir, en el apartado $a$, se aplicará la ley española siempre que no resulte aplicable ninguna de las leyes señaladas en el párrafo primero. La norma se inclina claramente hacia el favor divorcii, ya que se aplicará la ley española si con arreglo a la norma de conflicto del párrafo primero no se puede obtener la separación o el divorcio. Con este precepto, el Ordenamiento español podría correr el riesgo de convertirse en un "paraíso del divorcio» y, ello si tenemos en cuenta además los criterios tan amplios de competencia judicial internacional de nuestros tribunales otorgados por el ya citado Reglamento Comunitario ${ }^{33}$. Hemos de tener en cuenta además que, en el momento en que se produce la reforma del art. 107.2 del Código civil, la separación y el divorcio no constituían en nuestro Ordenamiento jurídico un derecho. El artículo 32 de la Constitución úni-

${ }^{33}$ Los criterios de competencia judicial internacional que establece el Reglamento para que se pueda demandar a una persona que, o bien sea nacional de un Estado miembro, o bien tenga su residencia habitual en un Estado miembro, son los siguientes (artículo 3): son competentes los tribunales del Estado 1. En cuyo territorio se encuentre. a) La residencia habitual de los cónyuges o b) La residencia habitual del demandado, c) El último lugar de la residencia habitual de los cónyuges, siempre que uno de ellos aún resida allí, o d) En caso de demanda conjunta: La residencia habitual de uno de los cónyuges of) La residencia habitual del demandante si ha residido allí durante, al menos un año, inmediatamente anterior a la presentación de la demanda, o g) La residencia habitual del demandante en el caso de que haya residido allí al menos los 6 meses inmediatamente anteriores a la presentación de la demanda y de que sea nacional del Estado miembro en cuestión, o en el caso del Reino Unido, que tenga allí su domicilio.

2. De la nacionalidad de ambos cónyuges o, en el caso del Reino Unido del domicilio común.

Asimismo, el art. 7 indica que si los tribunales de los Estados miembros no son competentes con arreglo a los criterios de competencia señalados en el Reglamento, podrán conocer de las causas de separación o divorcio, acudiendo a su sistema autónomo de competencia judicial internacional, de forma que ya no será necesario que el demandado sea nacional o residente habitual en un Estado miembro.

En el caso de España, estos criterios se encuentran en la Ley Orgánica del Poder Judicial, art. 22.3. Nuestros tribunales son competentes: a) Cuando ambos cónyuges posean residencia habitual en España al tiempo de la presentación de la demanda o b) El demandante sea español y tenga su residencia habitual en España o c) Cuando ambos cónyuges sean españoles, independientemente del lugar en el que residan, siempre que interpongan la demanda de mutuo acuerdo o uno con el consentimiento del otro. Todo ello con independencia de que hagan uso de los foros generales contenidos en el art. 22.2 de la LOPJ; es decir, de la sumisión tácita o expresa y del domicilio del demandado en España.

En este último caso, según el art. 7.2 del Reglamento, estos criterios autónomos de competencia los podrá invocar un residente habitual en España en igualdad de condiciones que los españoles, aunque la parte contra la que demande no sea residente habitual ni nacional de un Estado miembro. 
camente indicaba lo siguiente: «El hombre y la mujer tienen derecho a contraer matrimonio con plena igualdad jurídica. La ley regulará las formas de matrimonio, la edad para contraerlo, los derechos y deberes de los cónyuges, las causas de separación y disolución y sus efectos». Hoy en día esta situación ha experimentado un cambio considerable y la Ley 15/2005 de 8 de julio por la que se modifica el Código civil y la Ley de Enjuiciamiento Civil en materia de separación y divorcio ${ }^{34}$, de acuerdo con el artículo 32 de la Constitución "persigue ampliar el ámbito de libertad de los cónyuges en lo relativo al ejercicio de la facultad de solicitar la disolución de la relación matrimonial». A tal efecto y, de acuerdo con el respeto al libre desarrollo de la personalidad, garantizado en el artículo 10.1 de la Constitución, se reconoce «el derecho de la persona a no continuar casada».

Como podemos observar, la modificación del artículo 107.2 del Código civil se adelanta, en cuanto al reconocimiento del derecho al divorcio, a la reforma operada en el año 2005, lo cual, si bien es digno de ser calificado de forma positiva, también presenta el riesgo de que nuestros tribunales emanen resoluciones judiciales claudicantes.

Por otra parte y, como ha sido puesto de relieve por algunos autores ${ }^{35}$, este precepto conlleva ciertas lagunas legales que no son resueltas. Así, éste será el supuesto en el que los cónyuges tengan distinta nacionalidad, no siendo ninguna de ellas la de un Estado miembro y que residan habitualmente en España, pero comenzada la crisis matrimonial cada uno de ellos decide volver a su país de origen y a los pocos meses y, de común acuerdo, presentan la demanda de separación ante los tribunales españoles, al ser éste el último lugar de la residencia habitual común del matrimonio. Los tribunales españoles serán competentes a tenor de la sumisión expresa de las partes, foro de competencia que se contempla en el artículo 22.3 de la LOPJ, el cual será aplicable a tenor del artículo 7 del Reglamento Comunitario 2201/2003 ${ }^{36}$. Llegado el momento de determinar la ley aplicable al fondo del asunto, ya

${ }^{34}$ BOE, num. 163 de 9 de julio de 2005.

${ }^{35}$ Esta cuestión es puesta de relieve por Diago Diago, M. P., «La nueva regulación española de las crisis matrimoniales ante el impacto de la multiculturalidad», en El derecho de familia ante el siglo XXI: aspectos internacionale, Dir. por A. L. CALVO CARAVACA y E. CASTELlANos RuIZ. Madrid 2004, p. 287 y por CAMPuZANo DíAZ, B., «Consideraciones acerca de la reforma del art. 107 del Código civil», en El derecho de familia ante el siglo XXI: aspectos internacionales, Dir. por A. L. CAlvo Caravaca y E. Castellanos Ruiz. Madrid 2004, p. 188, las cuales siguen a CALVo CARAVACA, A. L. y CARRASCosa GonZÁlez, J., «Crisis matrimoniales», AA.VV., en Derecho internacional privado. Vol. II, Madrid, 2003, p. 158.

${ }^{36}$ La sumisión expresa a los tribunales españoles sí que podrá ser efectiva en las demandas de separación o divorcio efectuadas por los cónyuges de mutuo acuerdo, ya que el artículo 770 de la LECv indica que las demandas de nulidad, separación o divorcio que no sean de mutuo acuerdo (a las que se refiere el artículo 777) se sustanciarán por los trámites del juicio verbal. En esta línea, el artículo 54 de la LECv señala lo que sigue: «Tampoco será válida la sumisión expresa o tácita que deban decidirse por el juicio verbal», de manera que 
que las conexiones del párrafo primero del artículo 107 no resultan aplicables al no concurrir ninguna de ellas en el supuesto, al no residir en España ninguno de los cónyuges, ni tener tampoco ninguno de ellos la nacionalidad española, no procedería el pronunciamiento de nuestros tribunales sobre la separación o el divorcio, ya que el precepto no establece la solución a adoptar. En este caso, el precepto debería de establecer la aplicación de la ley española como lex civilis fori; es decir, cuando los tribunales españoles sean competentes, como así lo hacía el artículo 107.2 del Código civil antes de ser modificado.

Asimismo, este criterio puede operar cuando no se haya alegado y probado en el proceso el derecho extranjero aplicable a la separación judicial o el divorcio, según los criterios del párrafo primero; es decir, cuando la ley de la nacionalidad o de la residencia habitual común, así como la última ley nacional común del matrimonio si uno de los cónyuges aún reside allí, sea una ley extranjera. Esto nos conduciría nuevamente a la aplicación de la ley material española, pero no ya porque no se haya probado ni alegado el Derecho extranjero (artículo 281.2 LECv), sino por mandato del apartado $b$ del inciso $2 .^{\circ}$ del artículo 107.2 del Cc. Así, tendrían plena vigencia, a pesar de la modificación del artículo $107.2 \mathrm{del} \mathrm{Cc}$, las resoluciones judiciales que, para evitar el no dictar una separación o un divorcio, acudían al mecanismo de la no probanza del Derecho extranjero, necesaria y obligatoria según el artículo 281.2 de la LECv.

b) En el segundo supuesto; esto es, en el apartado $b$, parece que la aplicación de la ley española se ha de hacer de forma automática cuando los cónyuges presenten la demanda de divorcio o separación ante los tribunales españoles de mutuo acuerdo o uno con el consentimiento del otro incluso, como apunta B. Campuzano Díaz, aun cuando no sea ésta la voluntad de los cónyuges $^{37}$, interpretación que no queda avalada por el objetivo de la reforma, pero que sí lo está a tenor de su tramitación parlamentaria, toda vez que el Grupo Parlamentario Socialista presentó una enmienda poniendo de manifiesto este extremo y ésta no fue aceptada ${ }^{38}$. Precisamente ésta es la interpre-

el foro de la sumisión expresa no opera en los divorcios o separaciones contenciosas. Estos preceptos impiden que dos cónyuges que ostentan la misma nacionalidad puedan divorciarse con arreglo a su ley nacional común en el caso de un proceso no contencioso. Vid. AreNAS GARCíA, R., Crisis matrimoniales internacionales, Santiago de Compostela, 2004, p. 123 y ss.

${ }^{37}$ Campuzano Díaz, B., Consideraciones acerca de la reforma del art. 107..., Ob. Cit., p. 190.

${ }^{38}$ Esta enmienda (la num. 189), fue justificada por el Grupo Parlamentario Socialista indicando que «La letra b) del apartado 2 del texto del Proyecto lleva en realidad al absurdo de que a los cónyuges extranjeros que presenten solicitud de separación o divorcio de mutuo acuerdo se les imponga el Derecho español, lo que no tiene sentido, ni se justifica ni es congruente con el apartado 2 del artículo». BOCG, Congreso de los Diputados, VII Legislatura, Serie A; Proyecto de Ley 13 de mayo de 2003, Num. 136-8, Enmienda, p. 90. 
tación que realiza M. P. Diago Diago ${ }^{39}$, al entender que este apartado constituye un espacio idóneo para que los cónyuges ejerciten la autonomía de la voluntad, ya que podrán elegir en su demanda la aplicación de la ley española y no la aplicación de la ley nacional común o de la residencia habitual común si presentan la demanda de mutuo acuerdo ante los tribunales españoles. No obstante esta interpretación, hemos de señalar que esta puntualización no fue aceptada en la tramitación de la ley, ya que en la enmienda presentada por el Grupo Socialista se solicitaba que el texto indicara lo siguiente: «En todo caso se aplicará la ley española cuando uno de los cónyuges sea español o resida habitualmente en España en el momento de la presentación de la demanda si... b) Lo solicitan ambos cónyuges en la demanda presentada de mutuo acuerdo o por uno con el consentimiento del otro». De manera que hemos de concluir que el precepto puede conducir a errores en cuanto a su aplicación, ya que el intérprete jurídico puede deducir de su tenor que la aplicación del derecho español es obligatoria en este supuesto y no queda a la elección de las partes a través de su indicación expresa en la demanda.

c) En el tercer supuesto; es decir, en el apartado $c$, se aplicará la ley española si las leyes señaladas en el párrafo primero no reconocieran la separación o el divorcio o lo hicieran de forma discriminatoria o contraria al orden público. Nuevamente se instituye el favor divorci, al plasmarse el texto de la enmienda al Proyecto de la Ley 30/1981 de 7 de julio, que en su día no se aceptó, y ello porque se aplicará la ley española siempre y cuando la norma extranjera aplicable no reconozca o no regule la separación o el divor$\mathrm{cio}^{40}$. Asimismo y, para lograr la efectividad del favor divorci, la ley extranjera aplicable no sólo no ha de reconocer la separación judicial o el divorcio, sino que basta con que el reconocimiento de estas instituciones sea realizado por la normativa foránea de una forma discriminatoria o contraria al orden público.

${ }^{39}$ Diago Diago, M. P., «La nueva regulación española de las crisis matrimoniales ante el impacto de la multiculturalidad», Ob. Cit., p. 291. La autora indica que la aplicación de la ley española puede conducir a que el divorcio y la separación se rijan por una ley que ya nada tiene que ver con el matrimonio, como sería el supuesto de una pareja de italianos con residencia habitual en Italia y que, tras la ruptura de la relación, uno de los cónyuges se traslada a España y sitúa aquí su residencia habitual. Al cabo de un año deciden interponer de mutuo acuerdo la demanda de divorcio ante los tribunales españoles, dándose el caso de que se aplicará al fondo la ley española, ley con la cual no ha tenido ninguna vinculación el matrimonio.

${ }^{40}$ Esta enmienda rezaba del siguiente modo: «No obstante, si la ley extranjera aplicable conforme a lo dispuesto en el párrafo anterior, no admite la disolución de matrimonio por divorcio, se aplicará la ley española si uno de los cónyuges es español y tiene su residencia habitual en España». Vid. González CAmpos, J. D. y Abarca Junco, P., «Matrimonio y divorcio», en Comentarios al nuevo Título IV del Libro Primero del Código civil, Madrid, 1990, p. 910. 
Así, es posible, como sucede en determinados Ordenamientos jurídicos, que no exista la separación judicial, pero sí el divorcio (Alemania, Rumanía, Países Escandinavos, etc.). En este caso, como así lo han determinado ciertas resoluciones de nuestros tribunales, como si obrara un mecanismo en estos ordenamientos para disolver el matrimonio, si el nacional de uno de estos ordenamientos presenta ante nuestros tribunales una demanda de separación y ley aplicable es la de su nacionalidad, en lugar de aplicar la ley material española lo que procede es denegar la demanda de separación e indicarle al demandante que interponga la acción de divorcio ${ }^{41}$.

De esta forma, se consagra la excepción del orden público en su efecto positivo; es decir, se sustituye la ley extranjera que es discriminatoria o contraria al orden público internacional español, por la aplicación de la ley española. Así, nos encontramos ante una "cláusula especial de orden público», que obliga al aplicador del Derecho a tener en consideración esta institución en una materia y circunstancias determinadas, ya que la excepción de orden público internacional presenta un carácter general, de forma que insta al juez a tenerla presente en estos supuestos en concreto ${ }^{42}$. No obstante, el establecimiento de este supuesto ha sido duramente criticado por algunos autores ${ }^{43}$ al entender que si, como describe el Defensor del Pueblo en su recomendación, en nuestro sistema se aplican normas extranjeras contrarias al orden público, tal vez la atención del legislador se debería de centrar en el mecanismo del artículo 12.3 del Código Civil ${ }^{44}$ y no abordar de forma individualizada cada uno de los ámbitos en los que esta excepción no es observada. A

${ }^{41}$ Sentencia de la AP de Santa Cruz de Tenerife de 28 de junio de 2004. Anteriormente, la sentencia de la AP de Madrid de 22 de junio de 2001 (sección 22) (Aranzadi Westlaw.es 2001AC/2001/1539), al entender que dado que la normativa marroquí no contempla, al contrario que la española, la separación judicial, «... podría plantear un problema atinente a la posible exclusión de la legislación de origen de los litigantes, para aplicar la ley española, por entender que aquella fuera contraria al orden público de conformidad con lo prevenido en el art. 12.3 del Código civil. Sin embargo, no puede llegarse a tan excepcional criterio de exclusión, dado que la legislación del reino de Marruecos contempla específicamente soluciones a la crisis matrimonial que no cabe, en modo alguno, calificar de anómalas, en cuanto contrarias al orden público, ya sea interno español, ya el internacional, pues se encauzan aquellas, bien a través del repudio, bien del divorcio judicial, que producen la disolución del vínculo conyugal...».

${ }^{42}$ Vid. sobre este tipo de cláusula y su función, QuiÑonEs EscámEZ, A., Derecho e inmigración: el repudio islámico en Europa, Ob. Cit., p. 55.

43 JuÁrez PÉREZ, P., «Hacia un derecho internacional privado intercultural», Ob. Cit., pp. 341-342. En el mismo sentido Diago Diago, M. P., «La nueva regulación española de las crisis matrimoniales..., Ob. Cit., p. 288, quien indica que la referencia al orden público debería ser suprimida porque no aporta nada nuevo y, sin embargo, introduce una gran dosis de inseguridad.

${ }^{44}$ Este precepto consagra la excepción de orden público internacional indicando al efecto lo siguiente: «En ningún caso tendrá aplicación la ley extranjera cuando resulte contraria al orden público». 
mayor abundamiento, lo que verdaderamente resulta preocupante es que los jueces españoles muestren dudas respecto de los derechos fundamentales de la mujer. Si ello es así y nuestros juzgadores no conocen el contenido del orden público internacional en materia matrimonial, lo más lógico sería acudir al Tribunal Constitucional para que éste proceda a su delimitación.

A nuestro juicio, la previsión de la aplicación de la ley española que se establece en este inciso resulta a todas luces innecesaria, ya que si la ley extranjera produce efectos discriminatorios en cuanto a la regulación de la separación judicial o el divorcio nunca será de aplicación por nuestros tribunales a tenor del juego del artículo 12.3 del Código civil, que impide la aplicación de una norma extranjera que sea contraria al orden público internacional español, en cuyo defecto se aplicará la ley material española. A mayor abundamiento, esta regulación resulta del todo absurda, ya que podría deducirse que se aplicará la ley española, a tenor de este último inciso del párrafo $2 .^{\circ}$ del artículo 107.2 del Código civil, si la ley extranjera es contraria al orden público internacional español en materia de separación y divorcio si alguno de los cónyuges es español o reside habitualmente en España, y en todos los demás casos la ley extranjera contraria al orden público internacional español será rechazada por el juego del art. 12.3 del Código civil, lo cual es ilógico desde todo punto de vista.

\section{BASES PARA UNA REFORMA DEL ARTÍCULO 107.2 DEL CÓDIGO CIVIL}

A mi juicio, la reforma del artículo 107 del C.c. se ha basado en ciertas tendencias del Derecho internacional privado comparado, las cuales conducen a la aplicación de la lex fori cuando el Derecho extranjero aplicable según la norma de conflicto no reconoce el divorcio y la separación o lo hacen de una forma discriminatoria. Así, la Ley Suiza de Derecho internacional privado de 1987 establece lo siguiente: «Mientras el Derecho nacional extranjero común no permita la disolución del matrimonio o lo someta a condiciones extraordinariamente severas, el Derecho suizo es aplicable si uno de los esposos es igualmente suizo o si uno de ellos reside desde hace dos años en Suiza». En Francia existe una propuesta presentada ante la Asamblea Nacional para completar el artículo 310 del C.c., que establece que se aplicará la ley francesa «... cuando la ley extranjera competente reserve la iniciativa del divorcio o la separación al cónyuge de sexo masculino o de manera general comporte disposiciones contrarias a la igualdad de los derechos entre los esposos y en sus relaciones con respecto de los hijos en la disolución del matrimonio ${ }^{45}$.

${ }^{45}$ Esta propuesta no ha prosperado. Vid. comentario por LESCASTREYRES, M-H., «Le divorce en Droit internacional privé français (article 310 de Code civil)», AA.VV, en El derecho de familia ante el siglo XXI: aspectos internacionales, Dir. por A. L. CALvo CARAvaCA y E. CASTEllanos Ruiz, Madrid, 2004, pp. 531-546. 
Todas estas consideraciones nos llevan a la conclusión de que hubiera sido suficiente para evitar las discriminaciones sufridas por la mujer que el precepto en su reforma hubiera consagrado la autonomía de la voluntad tal y como había indicado el Defensor del Pueblo en su recomendación; eso sí, la norma tendría que haber dejado claro que la elección entre la ley de la nacionalidad o de la residencia habitual tendría que efectuarse necesariamente por la parte demandante, que en la mayoría de los casos será la mujer, para evitar imposiciones del hombre, parte más fuerte en este tipo de relaciones; si la elección la realizara el hombre y la ley elegida por él fuera discriminatoria en relación con la mujer, bastaría su inaplicación por los tribunales españoles al ser contraria al orden público internacional español. En definitiva:

Ésta había sido la reforma anteriormente reivindicada por la doctrina ${ }^{46}$, y era además una de las orientaciones mantenidas por el Grupo Europeo de Derecho Internacional Privado, que se dirige a ofrecer una opción limitada de leyes a las partes y, en defecto de elección, una norma de conflicto con conexiones en cascada ${ }^{47}$. Ésta constituye también una tendencia de la regulación de la separación y el divorcio en Derecho internacional privado comparado. Así, en la reforma legislativa llevada a cabo en los Países Bajos en 1981, se introdujo la posibilidad de optar por la aplicación de la ley holandesa con independencia de la nacionalidad de las partes y del lugar de la residencia habitual ${ }^{48}$. En este mismo sentido, el Código belga de Derecho internacional privado de 16 de julio de 2004 establece en su artículo 55 la posibilidad de que las partes elijan la ley aplicable a los divorcios de mutuo acuerdo.

Entendemos que, de una forma implícita, ésta ha sido la solución en nuestro Derecho hasta la reforma operada en el artículo 107.2 del Código civil por la Ley de 2003. Así, la autonomía de la voluntad entre la elección de la ley nacional común de los esposos (primera conexión con efecto bloqueante) y la ley de la residencia habitual común, cuando ambos residían en España, regía la separación judicial y el divorcio como consecuencia de la interpretación que los tribunales españoles realizaban del anterior artículo 107.2 del Código civil, en relación con la no alegación y prueba por las par-

\footnotetext{
${ }^{46}$ AbARCA JunCO, P., «La regulación de la sociedad multicultural», en Estatuto personal y multiculturalidad de la familia, coordinado por A. L. CALvo CARAVACA y J. L. IRIARTE Ángel, Madrid, 2000, p. 169. BlanCo-Morales Limones, P., «Crisis matrimoniales», Ob. cit., pp. 121 y ss.

${ }^{47}$ Vid. resumen de la última reunión de este grupo realizada por J. D. GonZÁlez CAMPOS y A. BorRás RodrígueZ, en Revista Española de Derecho internacional, 2002/2, pp. 1066 a 1068, esp. p. 1068. Los trabajos de este Grupo también se pueden consultar en $<$ http://www.drt.ucl.ac.bc/gedip >.

${ }^{48}$ EnTZINGER, H., «L'inmigrationaux Pays-Bas du pluriculturalisme à l'integration», en Racisme et modernité, M. Wieviorka, París, 1993, pp. 400-415.
} 
tes del Derecho extranjero aplicable a la separación judicial y al divorcio. En efecto, constituye una regla en nuestro Ordenamiento jurídico que el derecho extranjero aplicable al fondo de una relación jurídica internacional ha de ser alegado y probado por las partes ${ }^{49}$. Si, como consecuencia de la aplicación de la primera conexión del artículo 107.2 del Código civil, la separación judicial o el divorcio se regían por una ley extranjera, como ley nacional común del matrimonio y esta norma foránea no era alegada y probada por las partes, nuestros tribunales, lejos de arbitrar un non liquen, lo cual supondría una violación del derecho a la tutela judicial efectiva consagrado en el artículo 24 de la Constitución, aplicaban la ley material española, ley de la última residencia habitual común del matrimonio; es decir, por vías distintas se llegaba a la misma solución, si bien ésta tenía lugar siempre y cuando ninguna de las partes probara y alegara el Derecho extranjero aplicable, con lo cual, en la mayoría de los supuestos, el Derecho español se aplicaba a la separación judicial y al divorcio por mutuo acuerdo de las partes.

Esta posibilidad de dejar a las partes la elección del Derecho aplicable cuando el Derecho extranjero que, según la norma de conflicto española es de aplicación, ha sido puesta de manifiesto por nuestros tribunales. En concreto, la sentencia de la AP de Barcelona de 30 de abril de $2002^{50}$ indica esto: «La separación debería regirse por la ley marroquí (ley nacional común de los cónyuges), la cual, sin embargo, no ha sido alegada ni probada por ninguna de las partes. Ante tales circunstancias es doctrina reiterada del TS que si no se alega ni aprueba el derecho extranjero deberá juzgarse y fallarse según la ley material española... como lex fori. A pesar de que por esta vía se pueda incurrir en el riesgo de dejar a la elección de las partes la cuestión del derecho aplicable (puede no interesarles alegar el derecho extranjero designado por la norma de conflicto, prefiriendo, en cambio, la lex fori), según el Tribunal Constitucional, la doctrina jurisprudencial de que en defecto de prueba del derecho extranjero debe estarse al derecho español es más respetuosa con el artículo 24.1 de la Constitución española... que la solución de tener por decaída la demanda, dado que el derecho español con carácter sustitutorio del que resulta aplicable, también puede ofrecer en una situación de tráfico externo la respuesta fundada en derecho que el precepto constitucional citado exige...».

${ }^{49}$ Sobre esta cuestión, vid. con carácter general, CALvo CARAVACA, A. L. y CARRASCosa GonZÁLEZ, J., Derecho internacional privado, 9. a ed., Granada, 2008, pp. 307-338. y bibliografía allí citada., pp. 307-308.

${ }^{50}$ Aranzadi Westlaw JUR/2002/185582. En igual sentido Sentencia de la AP de Almería de 28 de junio de 2004, Aranzadi Westlaw AC/2004/1440 y las sentencias citadas por ambas dirigidas en la misma dirección. 
La crítica a esta situación desde la vertiente del «Derecho internacional privado social de la inmigración ${ }^{51}$ radica fundamentalmente en que con ella se deja en manos de las partes la aplicación de uno u otro Derecho, lo cual puede originar que se produzcan situaciones claudicantes; es decir, válidas desde el punto de vista de nuestro Ordenamiento jurídico, pero sin efectividad desde la óptica del Ordenamiento de origen del extranjero, lo que se opondría al derecho a la tutela judicial efectiva consagrado en el artículo 24.1 de la Constitución ${ }^{52}$. No cabe duda de la existencia de esta posibilidad; sin embargo, no hemos de perder de vista que, con esta actitud, los litigantes se están manifestando de una forma tácita hacia la resolución de su conflicto a tenor de un determinado Derecho y que conocen las consecuencias de la inaplicación de su Derecho de origen.

El empleo por las partes de este mecanismo nos pone de manifiesto las carencias que la actual norma de conflicto conlleva, en cuanto a posibilitar una respuesta adecuada a las situaciones de las personas cuyas vidas transcurren entre dos Ordenamientos jurídicos: el de acogida y el de origen ${ }^{53}$. La no alegación y prueba del Derecho extranjero aplicable a la separación y al divorcio, según la norma de conflicto española, se nos muestra bastante significativa, no sólo actualmente, sino desde hace ya bastante tiempo. De esta forma entendemos con G. Esteban de la Rosa que la norma de conflicto es funcional al «método de reconocimiento», en el sentido de que «reclama a través de su punto de conexión el ordenamiento aplicable, pero no hace una mera o estricta remisión localizadora, sino que halla el sistema jurídico que se encuentra más estrechamente vinculado con la situación, de tal forma que

\footnotetext{
${ }^{51}$ Esteban DE La Rosa, G., «El nuevo Derecho internacional privado de la inmigración», REDI, 2007, num.1, p. 103 y ss. Id., «La multiculturalidad (de inmigración) relevante para el sistema español de Derecho internacional privado», Rev. Jurídica de la Univ. De Santiago de Compostela, 2007, Vol. 16, num. 2, pp. 5-26.

${ }^{52}$ Para evitar esta situación, la sentencia de la AP de Barcelona de 8 de junio de 2006 (Aranzadi Westlaw JUR 2007/19193), aplica de oficio en un proceso de divorcio el Derecho marroquí, la ser la ley nacional común de los esposos, sin que las partes alegaran y probaran dicho derecho. La AP entiende que son de aplicación los artículos 98 y ss. del Código de Familia Marroquí de 2004, interpretándolos según su criterio, sin exigir el informe de dos jurisconsultos extranjeros, tal y como dispone nuestro Ordenamiento jurídico, lo cual desde nuestra óptica se opone frontalmente a la línea seguida por nuestro Ordenamiento y es criticable desde todo punto, en tanto en cuanto la interpretación que del precepto extranjero puedan hacer nuestros tribunales es posible que no sea la correcta de acuerdo con el ordenamiento jurídico al cual pertenece la norma extranjera. En contra de esta interpretación, Esteban De la Rosa, G., OuAld, A y SaghiR, S., en comentario a esta sentencia en REDI, 2007, num. 1, pp.304-308.

${ }^{53}$ SÁNCHEZ LoREnZo, S. A., «Globalización, pluralidad cultural y Derecho internacional de la familia», Anuario Hispano-Luso-americano de Derecho internacional, 2005, pp. 101 y ss.
} 
se promueva que la decisión sea reconocida en dicho Estado con el que la persona se encuentra vinculada de forma mas estrecha» ${ }^{54}$.

Ésta es la orientación que actualmente se sigue en el Libro Verde presentado por la Comisión Europea sobre la ley aplicable a la competencia en asuntos de divorcio ${ }^{55}$, de manera que el Estado español se ha pronunciado a favor de que las partes, cuando el divorcio sea por mutuo acuerdo, puedan ejercitar la autonomía de la voluntad, no sólo eligiendo entre la ley de su nacionalidad o residencia habitual común, sino extendiéndola a otras leyes, como la nacionalidad o la residencia habitual de cualquiera de los cónyuges. En defecto de elección regiría la ley con la que el matrimonio haya estado más estrechamente vinculado, presumiéndose que ésta es la ley de la última residencia habitual común del matrimonio.

\section{CONCLUSIONES}

Con la reforma del artículo 107 del Código civil se posibilita que las mujeres de religión musulmana se puedan divorciar o separar de acuerdo con la ley española; sin embargo, las críticas a esta modificación se centran también en la previsible existencia de resoluciones claudicantes desde el momento en que esta resolución dictada por los tribunales españoles no va a gozar de reconocimiento ni eficacia en el país de origen de la mujer, ya que, según la normativa de los Estados musulmanes, el estatuto personal se rige por la ley nacional de la persona, que es irrenunciable, y se considera que el no acatamiento de esta ley supone como una especie de apostasía, lo que desemboca en la negación de la personalidad jurídica del individuo, o lo que es lo mismo, en una especie de muerte civil. La nacionalidad en los países del Magreb y en buena parte de los países del África subsahariana no se pierde nunca y sus ciudadanos han de actuar conforme a ésta ${ }^{56}$. De esta forma nos vamos a encontrar con situaciones en las que una mujer musulmana va a

${ }^{54}$ G. ESTEBAn DE LA RosA, «La multiculturalidad (de inmigración) relevante...», Ob. Cit. p. 21 .

${ }^{55} \mathrm{Vid}$., <http://www.ec.europa.eu/justice_home/news/consulting_public/>.

${ }^{56} \mathrm{El}$ art 2 del Código de Familia Marroquí promulgado por la Ley n. ${ }^{\circ} 7003$ de 3 de febrero de 2004 (Boletín Oficial n. ${ }^{\circ} 5184$ de 5 de febrero de 2004) y que derogó al Código de 1958, modificado en 1993, establece que será de aplicación a: 1. ${ }^{\circ}$ ) Todos los marroquíes, aunque tengan otra nacionalidad, $2 .^{\circ}$ ) Los refugiados, $3 .^{\circ}$ ) Las parejas en las que una de las partes sea marroquí y $4 .^{\circ}$ ) Las parejas de marroquíes en las que uno de ellos sea musulmán.

Sobre este tema, vid. con carácter general, Diago Diago, M. P., «La nueva Mudawana marroquí y el Derecho internacional privado», REDI, 2004, num. 2, pp. 1078-1083. FobleTs, M. C. y LoukiLI, M., «Mariage et divorce dans le nouveau Code marocain de la familla. Quelles implications pour les Marocains en Europe?», Revue Critique de Droit Internacional Privé, 2006, pp. 521 y ss. 
estar divorciada desde la óptica de nuestro sistema jurídico, pero va a permanecer casada desde el punto de vista del Estado de su nacionalidad ${ }^{57}$. No podemos negar la serie de inconvenientes que esta situación va a conllevar, pero, sin embargo, tenemos que argumentar en su favor que cuando una mujer musulmana decide divorciarse según la ley española y recurrir ante nuestros tribunales es porque implícitamente está dispuesta a asumir este riesgo y, porque entre otras cosas, desea que su marido cumpla con las obligaciones que el Ordenamiento jurídico español le impone como consecuencia del divorcio (pensión de alimentos, asignación de la vivienda, guarda y custodia de los hijos comunes, pensión compensatoria, etc.), aparte de la posibilidad que entraña el ser actora de una acción de separación o divorcio cuando la convivencia se hace insostenible como consecuencia del trato de primacía del que goza el hombre, malos tratos, sevicias, etc. La mujer musulmana que decide divorciarse de acuerdo con la ley española, por lo general, no tiene un proyecto de regreso a su país de origen, muy al contrario, en la mayoría de los casos su intención es permanecer en España y reanudar aquí su vida; por lo tanto, poco le importa que este divorcio no se reconozca en su país de origen. Por otro lado, si la mujer cuenta con una sentencia de divorcio va a poder gozar de las ayudas y subvenciones que, tanto el Estado Central, como las Comunidades Autónomas, tienen previstas para esta serie de situaciones, como prioridad en el acceso a puestos de trabajo, ayudas por hijos para guarderías, estudios, libros, viviendas de alquiler de protección oficial, etc.

Queda claro, por lo tanto, que la comparecencia ante un tribunal español en demanda de una separación judicial o un divorcio, supone la asunción de la justicia material administrada por dicho órgano y no la emanada del órgano del Estado de procedencia del extranjero, de manera que las consecuencias del pronunciamiento del órgano jurisdiccional español son asumidas desde un principio por el demandante.

Asimismo, no debemos perder de vista la necesaria reforma que debe realizarse del artículo 107.2 del Código civil, en relación con la consagración, en primer lugar, de la autonomía de la voluntad, dejando en manos de las partes el derecho aplicable a la separación judicial y al divorcio cuando éstos se promuevan de mutuo acuerdo y, en segundo lugar, estableciendo

${ }^{57}$ Así, el artículo 114 del Código de Familia Marroquí establece lo que sigue: «Los cónyuges podrán ponerse de acuerdo sobre el comienzo del final de la relación conyugal sin ninguna condición o con condiciones que no sean incompatibles con las disposiciones de este código»; y el artículo 128.2 señala esto: «Las sentencias emitidas por los tribunales extranjeros sobre el repudio, el divorcio, el repudio por compensación o la anulación, serán susceptibles de ejecución si fueron emitidas por un tribunal competente o se basaron en causas que no fuesen incompatibles con lo que establece este código para la finalización de la relación conyugal...». 
conexiones que no obedezcan a una estricta remisión localizadora, sino que permitan que la decisión ofrecida por nuestros tribunales sea reconocida por el Estado con el que la persona se encuentra más estrechamente vinculada. 